\title{
Analysis of Influential Factors of Think Tanks in Chinese Universities
}

\author{
Jiayin Liu ${ }^{1}$, Jilun $\operatorname{Li}^{1} \&$ Jing Qin ${ }^{1}$ \\ ${ }^{1}$ College of Economics and Management, Nanjing University of Aeronautics and Astronautics, Nanjing, China \\ Correspondence: Jilun Li, College of Economics and Management, Nanjing University of Aeronautics and \\ Astronautics, Nanjing, China. E-mail: 18200181059@163.com
}

Received: December 14, 2019

Accepted: January 16, 2020

Online Published: January 17, 2020

doi:10.5539/mas.v14n2p23

URL: https://doi.org/10.5539/mas.v14n2p23

\begin{abstract}
Based on the spreading mechanism of think tank influence in social paradigm, this paper constructs an I-RDPS influence factor model to analyze the influence factors of think tank influence in Chinese universities. Taking the think tanks in the "2018 CTTI College Think Tank and" Top 100 College Think Tank Report "'" (Guangming Daily,2019,p.16)as the research object, using the CTTI China Think Tank Index and the CNKI Database, and using python to crawl and sample this college think tank official WeChat public account data, to obtain samples Data. Using factor analysis, normal upper percentile method, and multiple regression analysis to quantify the sample data to obtain the coefficient of influence of each indicator on the influence of think tanks in Chinese universities.

By analyzing the results, conducting quantitative and qualitative analysis to check and evaluate the results, and finally to make recommendations for the development of new think tanks in Chinese universities: a strategic guideline based on research results and giving full play to the advantages of distinctive disciplines; using flat modern management; and improving social networks in the evaluation system Weight of influence, attach importance to the construction of new media; build a management information system that meets the needs of college think tanks, and attach importance to resource accumulation.
\end{abstract}

Keywords: university think tank influence, factor analysis, multiple regression analysis, normal distribution

\section{Definition of Think Tank Influence}

Think tanks, are professional research institutes that provide decision support for decision makers, with the purpose of influencing decision-making, with public interest as the ultimate guide. Think tanks began in the military field during World War II and were used to refer to places where experts and military consultants were gathered to formulate military battle plans and military strategies. Think tanks developed in the modern era of peace (Wang Lili, 2015, pp, 37-38). With the development of the economy and society, they have gradually become independent policy research consulting institutions. At today's important historical node, the establishment and development of think tanks have a significant role in promoting the development of the world, nations and nations.

This study attempts to explore the relationship between the think tank influence index and think tank influence index and the internal relationship between the indexes by constructing the influence factor model. The influence factor index is used as the independent variable and the influence force is used as the dependent variable to construct the influence factor model. The construction of the influencing factor model of this research is different from the construction of the think tank evaluation theory system. It does not take the evaluation results as the goal, but starts from the evaluation results to analyze which factors contribute to the influence, how much and how to contribute.

\section{Social Paradigm-Based Think Tank Influence Transmission Mechanism}

Taking the social structure as the analysis paradigm, the generation of think tank influence is divided into three structural levels: decision-making (core) influence, elite (central) influence, and mass (marginal) influence (Liang $\mathrm{X}, 2018$, pp:88-92). As a public policy research institution, think tanks are not only targeted at decision makers, but also at all levels of society. From the perspective of the demand side, the decision-maker's public policy is originally oriented to the whole society. Policies that meet the needs of decision makers and are accepted by both elites and the general public are ideal. But think tanks have different paths to spread influence across the entire hierarchy. They are oriented toward decision makers, that is, the demand layer. Think tanks will use research reports, policy consulting research projects, research hearings, experts, policy consulting, government lectures, etc. 
Passing information through the path; facing the elite is the central layer, the think tank will pass the research results in the form of academic journals, academic papers, and publications, and holding information such as academic conferences, training, and corporate consulting; Publishing media articles, websites, and new media, that is, social media, using television, the Internet, newspapers, and interview programs as the path to convey information. The social capital network is the stock of think tanks' social structure. The larger the scale of the think tank network and the higher the status of the network, the larger the stock of social capital. Therefore, the influence propagation path of the think tank based on the social structure paradigm is obtained.

The author makes detailed analysis based on the social structure analysis paradigm of the propagation path, hoping to refine the propagation path of the influence of think tanks to an observable dimension. The decision-making influence of think tanks is mainly achieved through the internal reference, reports submitted by various institutions to national or provincial and ministerial units, and research projects initiated by the national or provincial and departmental and unit-owned research projects. The elite influence of think tanks is achieved through academic journals, papers, and cited research results or opinions as the path. Mass influence is achieved by spreading ideas on social media to influence public opinion.

\section{Construction of I-RDPS Influencing Factor Analysis Mode}

\subsection{Selection of Research Objects}

The author initially selected all the college think tanks in the list of "2018 CTTI College Think Tank and" Top 100 College Think Tank Report "' as the research objects. The author's focus in this article is on the analysis of the influence of university think tanks, and to contribute to the construction and promotion of the influence of university think tanks by exploring the influencing factors of university think tank influence. Therefore, locating the research object as an excellent university think tank can better provide a reference and development direction for the construction of the influence of other think tanks.

In addition, the list of top 100 think tanks in colleges and universities is the list of think tanks in colleges and universities proposed by the most authoritative institutions in China so far. The China Think Tank Research and Evaluation Center of Nanjing University, as the leader of new think tank research with Chinese characteristics, has always had a high voice in the field of think tank research.

\subsection{Design of Indicator Variables}

By investigating the authoritative evaluation theory system and university think tank evaluation theory system, researching and analyzing the theory of think tank influence, and thinking and innovating, the author proposes an I-RDPS university think tank influence influence factor analysis model. Initial establishment for elaboration.

The I-RDPS university think tank influence influencing factor analysis model aims to explore the relationship between university think tank influence and university think tank resources, political decision outcomes, professional academic achievements and social network resource construction.

I-Influence indicator. The influence indicator as the dependent variable indicator of the IRDPS model is an indicator that is difficult to be quantified, and the results of ranking rankings are directly converted into influence indicators that violate the common sense of influence transmission. Based on the think tank 's social paradigm influence transmission mechanism and practical analysis of think tank influence, the author based on the Normal upper percentile model to rank the think tank influence rankings in the "2018 CTTI College Think Tank and" Top 100 College Think Tank Report "'. Quantitatively, I is the index of influence strength.

Resource indicator. University think tanks are independent research institutions attached to universities, and their influence is affected by the size of think tanks, human resources and funds. In addition, the internal governance structure and organizational platform background of university think tanks are also important resources on which think tanks exert their influence(Ahmad M, 2008, pp:79.). The I-RDPS model selects the number of years of establishment, the number of experts, and the number of branches or direct agencies as the quantitative indicators of resources.

Decision outcome indicator. As a non-profit organization for policy research and consulting, think tanks' influence on political decisions is the lifeline of think tanks (Segal H, Abelson D E, 2004, pp:128). The decision outcome indicator. is result-oriented. It attempts to explore the quantitative contribution of think tanks to the research results of political decision-making in the areas of governance, strategic planning, decision-making consultation, and so on. The author conducted data surveys to compare the quantity and quality of internal parameters (national, provincial and ministerial levels) (Paun, Akash, 2014,pp:295-300), and the number and quality of completed projects (national, provincial and provincial levels and below) And the number of reports issued as an indicator of the power of decision-making influence. 
Professional academic indicators. Improving think tank research efficiency, innovation ability, and competitiveness are closely related to the research results of think tanks in the professional field. In addition to exerting influence on the decision-making (core) class, the influence of think tank institutions on the elite is also important. Professional academic achievements are an important window for the elite to convey ideas and opinions. The I-RDPS model uses a combination of media exposure quantity, literature quantity, and quality indicators to construct an influencing factor analysis model in the selection of indicators, including: the number of issues published by the think tank, the number of published books, the number of journal articles published by the think tank, the number of cited articles in the journal and the number of downloads of the journal articles.

Social influence indicators. According to the social paradigm-based think tank influence spreading model, think tanks have marginal influence. Although the effect and approach of marginal influence on political decision-making is not as direct as the internal participation report, according to the long tail theory, marginal influence in the "tail" of political decision-making contribution is also an important driving force for the influence of think tanks( Mcdonald L, 2014, pp:845-880) . In addition, in the current Internet era, the implementation and effect of any public policy will inevitably be influenced by public opinions. The author believes that the use of think tank portals is not suitable for college think tanks. Taking into account the actual situation, compared with traditional think tank portals, users are more inclined to use mobile terminals to obtain resource information (Mcnutt K, Marchildon G, 2009, pp:219-236). The author's survey of 100 college think tanks in the list found that 37 think tanks have independent WeChat public accounts. Therefore, the I-RDPS model in this paper uses the construction status of WeChat public account as an indicator of social network resource construction. Social influence indicators include the number of think tanks cited in newspapers that have been indexed in the CNKI newspaper database, the frequency of WeChat public account pushes, the number of WeChat public account tweets read and the number of likes.

I-RDPS influencing factor analysis model, description analysis and data processing of each index, 15 variables were extracted. This indicator can quantify the influencing factors, and facilitate the subsequent modeling and analysis of the think tank's influence.

Table 1. Variable design

\begin{tabular}{ccc}
\hline Code & Variable name & Calculation formula or data source \\
\hline X1 & Year of establishment & 2019- year established \\
X2 & Number of experts & CTTI Database \\
X3 & Number of branches or affiliates & CTTI Database \\
X4 & Number of think tank publications & CTTI Database \\
X5 & Number of books published & CTTI Database \\
X6 & Number of internal & CTTI Database(Weighted \\
calculation)
\end{tabular}




\section{Application of Models and Empirical Analysis}

\subsection{Processing of Data}

\subsubsection{Pretreatment of Decision Outcome Indicators}

In the indicators of decision outcomes, the author counted the number and level of think tank internal references and projects in the sample. The internal reference levels were divided into national-level internal references and provincial-level internal references. Project levels were divided into national-level projects, provincial-level projects, and provincial-level projects. The author made a survey on the evaluation indicators and evaluation of various think tank evaluation institutions, and chose to refer to the evaluation indicators and evaluation tables of MRPA think tank experts of the China Think Tank Research and Evaluation Center of Nanjing University. The MRPA evaluation indicators and evaluation tables have first-level indicators. Experts have second-level indicators: approved internal parameters and projects. The above three results are assigned on a piece-by-piece basis, where each piece of internal reference is assigned as follows: 30 points each for the national level, 20 points each for the sub-national level, 10 points for each provincial and ministerial level, and 5 points for the vice-provincial and ministerial levels. Each article; the value of each item of the project is: National Social Science Major / Ministry of Education Major 10 points each, National Social Science Focus / National Self-Education Focus 6 points each, National Social Science General / Youth Project 4 points each, Province There are 2 points for each ministerial project and 0.5 points for other projects.

The author takes the average of the internal reference assignments at the national and provincial levels, and normalizes the results to facilitate counting. Record each provincial and ministerial internal reference as 1 , and each national internal reference as 3.3. Similarly, for think tank projects, each general project is recorded as 1, each provincial and ministerial project is recorded as 4 , and each national project is recorded as 10 .

\subsubsection{Dimensional Processing}

The difference in the scale of university think tanks, the author found in the statistical data, the index data of large think tanks and small think tanks in order of magnitude difference. At the same time, the counting units are not the same between the indicators, which makes the indicators non-comprehensive, and the dimension of the indicators needs to be dimensionless. Considering that the original data obeys the distribution of influence, that is, the distribution is normal, the author uses the Z-score (Zero-mean normalization) standardization method to perform dimension processing on the index values.

Z-score normalization is also called standard deviation standardization. The processed data has a mean value of 0 and a standard deviation of 1 . The conversion formula is:

$$
x^{*}=\frac{x-\mu}{\delta}
$$

Among them $\mu$ is the average value of each index data, $\delta$ is the standard deviation of each index data.

\subsection{Factor Analysis}

When studying the influencing factors, there are $\mathbf{p}$ influencing variables, which are respectively denoted as $\boldsymbol{X}_{1}, \ldots \ldots \boldsymbol{X}_{\boldsymbol{p}}$, and these indicators constitute a -dimensional random vector, which is expressed as $\boldsymbol{X}=\left(\boldsymbol{X}_{\mathbf{1}}, \ldots \ldots \boldsymbol{X}_{\boldsymbol{p}}\right)^{\prime}$.Assume that the mean of the random vector $\boldsymbol{X}$ is $\boldsymbol{\mu}$ and the covariance matrix is . Suppose $\boldsymbol{X}$ is a column vector composed of $\mathbf{n}$ random variables, and $\boldsymbol{\mu} \boldsymbol{k}$ represents the expected value of the kth element, then the covariance matrix is:

$$
\begin{aligned}
\Sigma=E\left\{\left(X_{1}-\mu_{1}\right)\right\} & \\
= & {\left[\begin{array}{lllc}
E\left\{\left(X_{1}-\mu_{1}\right)\left(X_{1}-\mu_{1}\right)\right\} & E\left\{\left(X_{1}-\mu_{1}\right)\left(X_{2}-\mu_{2}\right)\right\} & \ldots & E\left\{\left(X_{1}-\mu_{1}\right)\left(X_{\mathbf{n}}-\mu_{\mathbf{n}}\right)\right\} \\
E\left\{\left(X_{2}-\mu_{2}\right)\left(X_{1}-\mu_{1}\right)\right\} & E\left\{\left(X_{2}-\mu_{2}\right)\left(X_{2}-\mu_{2}\right)\right\} & \ldots & E\left\{\left(X_{2}-\mu_{2}\right)\left(X_{n}-\mu_{n}\right)\right\} \\
\vdots & \vdots & \ddots & \vdots \\
E\left\{\left(X_{\mathbf{n}}-\mu_{\mathbf{n}}\right)\left(X_{1}-\mu_{1}\right)\right\} & E\left\{\left(X_{\mathbf{n}}-\mu_{\mathbf{n}}\right)\left(X_{2}-\mu_{2}\right)\right\} & \ldots & E\left\{\left(X_{\mathbf{n}}-\mu_{\mathbf{n}}\right)\left(X_{\mathbf{n}}-\mu_{\mathbf{n}}\right)\right\}
\end{array}\right] }
\end{aligned}
$$

Perform a linear transformation on $\boldsymbol{X}$ and represent the common factor $\boldsymbol{F}$ with the original variables, as shown below:

$$
\left\{\begin{array}{l}
F_{1}=\mu_{11} X_{1}+\mu_{12} X_{2}+\cdots+\mu_{1 p} X_{p} \\
F_{2}=\mu_{21} X_{1}+\mu_{22} X_{2}+\cdots+\mu_{2 p} X_{p} \\
F_{3}=\mu_{31} X_{1}+\mu_{32} X_{2}+\cdots+\mu_{3 p} X_{p}
\end{array}\right.
$$

Random combination of the original data can get different combinations to generate different common factors $\boldsymbol{F}$, 
which have different statistical characteristics. In order to get better results, we often want to make the variance of $\boldsymbol{F}_{\boldsymbol{i}}$ as large as possible and each principal component $\boldsymbol{F}_{\boldsymbol{i}}$ can be independent of each other.

due to,

$$
\operatorname{var}\left(F_{i}\right)=\operatorname{var}\left(\overrightarrow{\mu_{\boldsymbol{\imath}}^{\prime}} \quad X\right)=\overrightarrow{\boldsymbol{\mu}_{\boldsymbol{\imath}}} \boldsymbol{\Sigma} \overrightarrow{\mu_{\boldsymbol{\imath}}}
$$

And for any constant $\mathbf{C}$, the following formula holds:

$$
\operatorname{var}\left(\vec{c} \overrightarrow{\mu_{\imath}^{\prime}} \quad X\right)=c \overrightarrow{\mu_{\imath}^{\prime}} \boldsymbol{\Sigma} \overrightarrow{\mu_{\imath}} c^{\prime}=c^{2} \overrightarrow{\mu_{\iota}^{\prime}} \overline{\Sigma \mu_{\iota}^{\prime}}
$$

Due to the removal of the restriction on $\boldsymbol{\mu}, \operatorname{var}\left(\boldsymbol{F}_{\boldsymbol{i}}\right)$ may be arbitrarily large, which will make the problem meaningless. To solve this problem, the following restrictions need to be made on linear transformations:

$$
\begin{gathered}
\mu_{i}^{\prime} \mu_{i}=1 \text {, which is: } \\
\mu_{i 1}{ }^{2}+\mu_{i 2}{ }^{2}+\cdots+\mu_{p 1}{ }^{2}=1(i=1,2, \ldots p)
\end{gathered}
$$

$\boldsymbol{F}_{\boldsymbol{i}}$ and $\boldsymbol{F}_{\boldsymbol{j}}$ are independent of each other $(\boldsymbol{i} \neq \boldsymbol{j} ; \boldsymbol{i}, \boldsymbol{j}=\mathbf{1}, \mathbf{2}, \ldots, \boldsymbol{p})$;

$\boldsymbol{F}_{\boldsymbol{i}}$ satisfies decreasing columns, and its variance can reflect the degree of comprehensive raw data information.

\subsubsection{KMO and Bartlett Test}

It can be seen from Table 2 that the value of KMO reaches $0.573>0.5$, and the value of $\mathrm{P}$ is $0.000<0.001$. According to Bartlett's test, it can be seen that the sample data meets the requirements for principal component analysis.

Table 2. KMO and Bartlett test

\begin{tabular}{lcc}
\hline \multicolumn{2}{c}{ KMO Sampling suitability } & .573 \\
\hline & Approximate chi-square & 296.701 \\
Bartlett sphericity test & Degrees of freedom & 105 \\
& Saliency & .000 \\
\hline
\end{tabular}

4.2.2 Extract common factors and rotate

According to Table 3, given that the criterion for extraction to become a common factor is that the eigenvalue is greater than 1 , the 15 variables ultimately retain 5 factors. The eigenvalues of the three principal components are $4.166,3.198,1.570,1.293$, and 1.135 , the initial eigenvalue variance contribution rates are $27.771 \%, 21.317 \%$, $10.467 \%, 8.619 \%$, and $7.564 \%$, and the cumulative contribution rate reaches $75.738 \%$. It shows that the selected five principal components together can better represent the amount of original information, and the contribution rate of the first public factor and the second public factor is much larger than the latter three. Therefore, when investigating the influencing factors of university think tank influence, The first two public factors have a greater impact. 
Table 3. Explanation of total variance

\begin{tabular}{|c|c|c|c|c|c|c|c|c|c|}
\hline \multirow[t]{2}{*}{ ingredient } & \multicolumn{3}{|c|}{ Initial eigenvalue } & \multicolumn{3}{|c|}{ Extract load sum of squares } & \multicolumn{3}{|c|}{ Sum of rotation load squares } \\
\hline & total & $\begin{array}{c}\text { Variance } \\
\text { percentage }\end{array}$ & Cumulative\% & total & $\begin{array}{c}\text { Variance } \\
\text { percentage }\end{array}$ & Cumulative\% & total & $\begin{array}{c}\text { Variance } \\
\text { percentage }\end{array}$ & Cumulative\% \\
\hline 1 & 4.166 & 27.771 & 27.771 & 4.166 & 27.771 & 27.771 & 3.375 & 22.502 & 22.502 \\
\hline 2 & 3.198 & 21.317 & 49.088 & 3.198 & 21.317 & 49.088 & 2.656 & 17.710 & 40.212 \\
\hline 3 & 1.570 & 10.467 & 59.555 & 1.570 & 10.467 & 59.555 & 2.581 & 17.208 & 57.420 \\
\hline 4 & 1.293 & 8.619 & 68.173 & 1.293 & 8.619 & 68.173 & 1.423 & 9.487 & 66.907 \\
\hline 5 & 1.135 & 7.564 & 75.738 & 1.135 & 7.564 & 75.738 & 1.325 & 8.831 & 75.738 \\
\hline 6 & .828 & 5.519 & 81.257 & & & & & & \\
\hline 7 & .709 & 4.729 & 85.986 & & & & & & \\
\hline 8 & .557 & 3.711 & 89.697 & & & & & & \\
\hline 9 & .505 & 3.370 & 93.066 & & & & & & \\
\hline 10 & .330 & 2.201 & 95.268 & & & & & & \\
\hline 11 & .252 & 1.678 & 96.946 & & & & & & \\
\hline 12 & .186 & 1.237 & 98.183 & & & & & & \\
\hline 13 & .141 & .941 & 99.124 & & & & & & \\
\hline 14 & .095 & .632 & 99.757 & & & & & & \\
\hline 15 & .036 & .243 & 100.000 & & & & & & \\
\hline
\end{tabular}

The Influence indicator preliminary value $\boldsymbol{y}^{\prime}$ is as follows:

$$
y^{\prime}=0.278 F_{1}+0.213 F_{2}+0.105 F_{3}+0.086 F_{4}+0.076 F_{5}
$$




\subsubsection{Calculating Factor Loading Kernel}

Table 4 shows the coefficients of the components after normalizing the original variables, and five factor expressions can be obtained.

Table 4. Component score coefficient matrix

\begin{tabular}{|c|c|c|c|c|c|}
\hline & Ingredient 1 & Ingredient 2 & Ingredient 3 & Ingredient 4 & Ingredient 5 \\
\hline Year of establishment(X1) & .023 & -.129 & .394 & .007 & .033 \\
\hline Number of experts(X2) & .259 & .116 & -.044 & -.101 & -.093 \\
\hline Number of branches or affiliates(X3) & -.046 & .216 & -.152 & .476 & -.210 \\
\hline $\begin{array}{l}\text { Number of think tank } \\
\text { publications(X4) }\end{array}$ & .279 & .121 & .027 & -.125 & -.159 \\
\hline Number of books published(X5) & .263 & -.077 & .041 & .031 & .074 \\
\hline $\begin{array}{l}\text { Internal reference amount } \\
\quad \text { (weighted) (X6) }\end{array}$ & .027 & .137 & -.146 & -.587 & -.049 \\
\hline $\begin{array}{l}\text { the number of completed } \\
\text { projects(weighted) (X7) }\end{array}$ & .135 & -.126 & -.013 & .234 & .178 \\
\hline Number of reports(X8) & .269 & -.024 & .040 & -.036 & .028 \\
\hline Number of journals published(X9) & .027 & -.014 & .287 & -.089 & .124 \\
\hline $\begin{array}{l}\text { Number of Cited Papers per } \\
\text { Journal(X10) }\end{array}$ & -.011 & -.056 & -.021 & -.049 & .674 \\
\hline $\begin{array}{l}\text { Number of papers downloaded per } \\
\text { journal(X11) }\end{array}$ & -.001 & .262 & -.165 & .069 & .344 \\
\hline $\begin{array}{l}\text { Number of newspaper } \\
\quad \text { exposures(X12) }\end{array}$ & .002 & .354 & -.130 & -.011 & .107 \\
\hline Push frequency (month) (X13) & .063 & .283 & .096 & -.195 & -.273 \\
\hline $\begin{array}{l}\text { Average number of reads on WeChat } \\
\text { public account(X14) }\end{array}$ & .006 & .254 & .109 & .084 & -.142 \\
\hline $\begin{array}{l}\text { Average number of likes on WeChat } \\
\text { public account(X15) }\end{array}$ & -.021 & -.103 & .361 & .137 & -.131 \\
\hline \multicolumn{6}{|c|}{$\begin{aligned} F_{1}=0.023 X_{1}+ & 0.259 X_{2}-0.046 X_{3}+0.279 X_{4}+0.263 X_{5}+0.027 X_{6}+0.135 X_{7}+0.269 X_{8} \\
& +0.027 X_{9}-0.011 X_{10}-0.001 X_{11}+0.002 X_{12}+0.063 X_{13}+0.006 X_{14} \\
& -0.021 X_{15}\end{aligned}$} \\
\hline \multicolumn{6}{|c|}{$\begin{aligned} F_{2}=-0.129 X_{1} & +0.116 X_{2}+0.216 X_{3}+0.121 X_{4}-0.077 X_{5}+0.137 X_{6}-0.126 X_{7}-0.024 X_{8} \\
& -0.014 X_{9}-0.056 X_{10}+0.262 X_{11}+0.354 X_{12}+0.283 X_{13}+0.254 X_{14}-0.103 X_{15}\end{aligned}$} \\
\hline \multirow{2}{*}{\multicolumn{6}{|c|}{$\begin{array}{c}F_{3}=0.394 X_{1}-0.101 X_{2}-0.152 X_{3}+0.027 X_{4}+0.041 X_{5}-0.146 X_{6}-0.013 X_{7}+0.040 X_{8} \\
+0.287 X_{9}-0.021 X_{10}-0.165 X_{11}-0.130 X_{12}+0.096 X_{13}+0.109 X_{14}+0.361 X_{15} \\
F_{4}=0.007 X_{1}-0.044 X_{2}+0.476 X_{3}-0.125 X_{4}+0.031 X_{5}-0.587 X_{6}+0.234 X_{7}-0.036 X_{8} \\
-0.089 X_{9}-0.049 X_{10}+0.069 X_{11}-0.011 X_{12}-0.195 X_{13}+0.084 X_{14} \\
+0.137 X_{15}\end{array}$}} \\
\hline & & & & & \\
\hline \multicolumn{6}{|c|}{$\begin{aligned} F_{5}=0.033 X_{1}-0.093 X_{2}-0.210 X_{3}-0.159 X_{4}+0.074 X_{5}-0.049 X_{6}+0.178 X_{7}+0.028 X_{8} \\
+0.124 X_{9}+0.674 X_{10}+0.344 X_{11}+0.107 X_{12}-0.273 X_{13}-0.142 X_{14}-0.131 X_{15}\end{aligned}$} \\
\hline
\end{tabular}




\subsection{Influence Indicator Calculation}

The Influence indicator preliminary value $\boldsymbol{y}^{\prime}$ is as follows

$$
y^{\prime}=0.278 F_{1}+0.213 F_{2}+0.105 F_{3}+0.086 F_{4}+0.076 F_{5}
$$

The variable expression of $\boldsymbol{y}^{\prime}$ is obtained through the matrix of $\boldsymbol{y}^{\prime}$ and component score coefficients, which is:

$$
\begin{aligned}
y^{\prime}=0.023 X_{1}+ & 0.076 X_{2}+0.043 X_{3}+0.083 X_{4}+0.069 X_{5}-0.033 X_{6}+0.043 X_{7}+0.073 X_{8} \\
& +0.036 X_{9}+0.030 X_{10}+0.070 X_{11}+0.070 X_{12}+0.050 X_{13}+0.064 X_{14}+0.012 X_{15}
\end{aligned}
$$

Substitute the sample think-tank index data to obtain the preliminary value of the Influence indicator $\boldsymbol{y}^{\prime}$, and use the social paradigm theory (Xu Ming, 2012, pp:81-83) of think-tank influence to consider the distribution of think-tank influence as a numerical group conforming to the normal distribution, and calculate the sample group think-tank $\boldsymbol{y}^{\prime}$ means and variances. Since the index data has been standardized by Z-score, the mean calculation result is 0 and the standard deviation is 0.365 . Therefore, it is considered that the sample think tank Influence indicator conforms to a normal distribution model with a mean value of 0 and a standard deviation of 0.365 . The function expression is:

$$
\mathrm{N}=(0,0.365)
$$

The normal upper percentile model combined with the ranking of the top 100 think tanks in CTTI colleges and universities to influence the think tanks was finally calculated as Y. For example, for the 38th Jinan University Overseas Chinese Studies Institute, calculate the Influence indicator Y:

The 38th think tank on the list should be $38 / 100=38 \%$ and $\mathrm{T}(\mathrm{X})=0.38$, so the influence of this think tank on the sample group $\mathrm{N}=(0,0.365)$ is calculated by Influence indicator $\mathrm{Y}$ for:

\section{NORMINV $(1-0.38,0,0.365)$}

The calculated result is about 0.112 , and the Influence indicator Y of Jinan University's Overseas Chinese Studies Institute is 0.112 .

\subsection{Multiple Regression Analysis}

\subsubsection{T-Test Model}

Taking the five principal component factors extracted previously as independent variables, and the Influence indicator Y calculated previously as the dependent variable, the following model is established and subjected to multiple linear regression analysis:

$$
\Upsilon=\beta_{1} F_{1}+\beta_{2} F_{2}+\beta_{3} F_{3}+\beta_{4} F_{4}+\beta_{5} F_{5}+\varepsilon
$$

The $\beta$ coefficient and significance judgment results of the model are obtained in Table 5. It can be seen that a model was generated in which the retained variables are principal components F1, F2, and F5, because their significance $\mathrm{p}<0.1$, but F3 and F4 can be retained because it does not pass the $\mathrm{t}$ test. So we get the regression result model:

$$
\Upsilon=0.099 F_{1}+0.162 F_{2}+0.162 F_{5}-0.043
$$

Table 5. t-test model coefficients

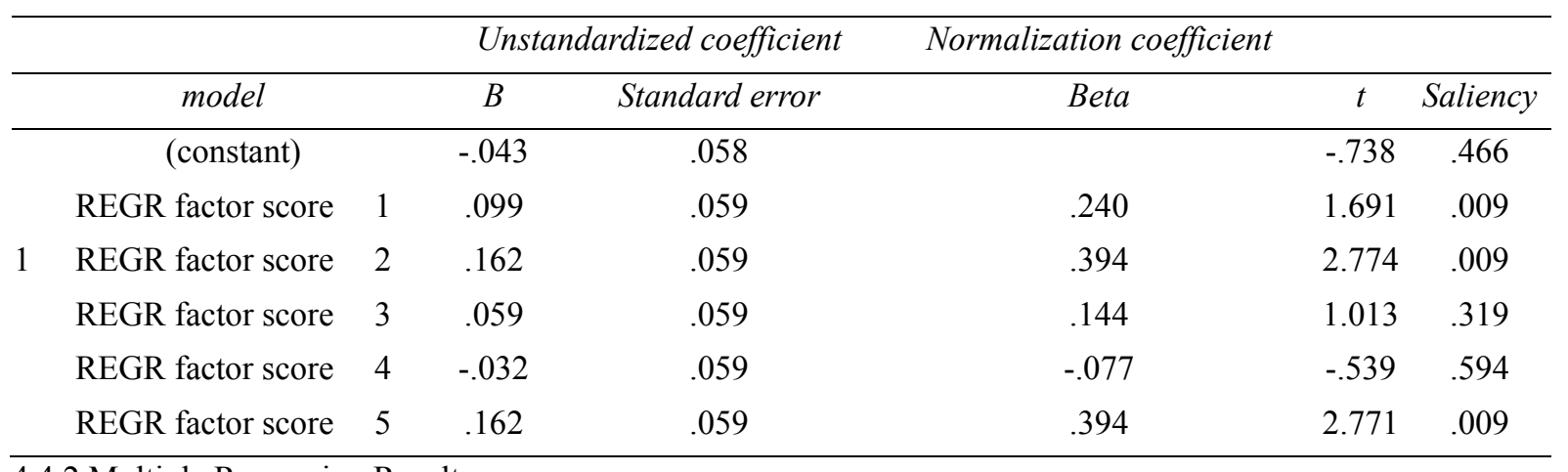

4.4.2 Multiple Regression Results

After t-test, F-test, and collinearity test on the model, the resulting model can be retained:

$$
\Upsilon=0.099 F_{1}+0.162 F_{2}+0.162 F_{5}-0.043
$$


The result is:

$$
\begin{aligned}
\Upsilon=-0.013 X_{1}+ & 0.029 X_{2}-0.004 X_{3}+0.021 X_{4}+0.026 X_{5}+0.017 X_{6}+0.022 X_{7}+0.027 X_{8} \\
& +0.020 X_{9}+0.099 X_{10}+0.098 X_{11}+0.075 X_{12}+0.008 X_{13}+0.019 X_{14}-0.040 X_{15}
\end{aligned}
$$

\section{Analysis of Influencing Factors}

From the results of multiple regression analysis, the 15 variables set in this study are ranked in descending order of their contribution to the Influence indicator; Number of Cited Papers per Journal, Number of papers downloaded per journal, Number of newspaper exposures, Number of experts, Number of reports, Number of books published, the number of completed projects(weighted), Number of think tank publications, Number of journals published, Average number of reads on WeChat public account, Number of internal references(weighted), WeChat public account push frequency(month), Number of branches or affiliates, Year of establishment and Average number of likes on WeChat public account.

\subsection{Professional Academic Indicators}

In the results of the I-RDPS influencing factor analysis in this study, the Professional academic indicators have the highest impact coefficient on the Influence indicator. The indicators. Number of published books, Number of think tank publications, and Number of journals published are located in the middle of the impact coefficient. Overall, professional academic indicators are undoubtedly the most important influencing factors in the analysis of influencing factors in this study.

University think tanks, as independent policy research institutions attached to universities, are specialized in the content and direction of research (Qiu Junping, Zu Wenling, 2018, pp: 101-108). They are the soul of university think tanks. If a university think tank wants to enhance its influence, it must have a solid professional research ability, implement the professional research ability and the transformation of academic research results, to give full play to its own advantages in the field of subject research. Integrate the research resources of advantageous and characteristic disciplines, and lay a solid foundation for the transformation of academic achievements-the results of asset and government services, so that university think tanks can get rid of a single academic research mechanism, maximize the auxiliary functions in the field of public policy decision-making, and meet the complex needs of policy decision-making.

\subsection{Decision Outcome Indicator}

Decision outcome indicators are the second most prominent indicator category in the analysis of influencing factors in this study. Among them, Number of reports is in the sixth position of the impact coefficient, and the impact coefficients of Number of completed projects(weighted) and Number of internal references(weighted) are in the middle position of all indicators.

First of all, from the perspective of the data source, in the process of obtaining indicators for Decision outcome indicators, the research uses the CTTI China Think Tank Index Source Think Tank Database, which was founded by the China Think Tank Research and Evaluation Center of Nanjing University. The CTTI database uses data from the think tank to fill in the application materials of the think tank resources, and the database creation unit reviews and enters the form based on the application materials and the factual evidence provided by the think tank. Therefore, the manual operation of the two nodes in the source think tank to fill in the reporting materials and the founding unit can cause a certain degree of error to the fact data.

In addition, according to the description of the index correlation coefficient matrix, it can be seen that the three indicators of the decision outcome indicators have a strong positive correlation with the indicators with a high impact coefficient in terms of correlation. The positive correlation between Number of completed projects(weighted) and Number of books published was 0.694 , the positive correlation between Number of reports and Number of books published was 0.602 , the positive correlation with Number of think tank publications was 0.64 , and the positive correlation with Number of experts reached 0.9. It can be seen that there is a resonance between the decision outcome index and the index with a high impact coefficient, which leads to the dilution of the influence coefficient of the correlation coefficient with the high rank index in the multiple regression analysis, which causes the impact coefficient of the decision outcome index to fall short of expectations.

\subsection{Social Influence Indicators}

Social influence indicators are relatively weak in the analysis of influencing factors in this study, and traditional media and new media indicators show a strong polarization. Among them, the coefficient of influence of the number of newspapers and periodicals exposed as a measure of traditional media ranked third, reaching 0.075 . In 
contrast, the average reading, WeChat, and push frequency indicators of WeChat public account of new media ranked 10th, 15th, and 12th, respectively, with impact coefficients of $0.019,0.008$, and -0.040 , respectively.

In the process of analyzing the Social influence indicators of university think tanks, by comparing the two major indicators of traditional media newspapers and mobile Internet social new media WeChat public account, we found that traditional media has better policy guidance than mobile new media. The effect of public opinion dissemination. University think tanks, as the largest number of think tanks and a public policy research institution, still need to work hard to develop in the influence of mainstream traditional media. Being recognized by the mainstream media, that is, the mainstream newspapers and news media, enables think tanks to be better understood by policy makers, to have a voice in capital services, to open channels for research results, and to achieve the purpose of increasing the influence of think tanks. On the contrary, the new media focused too much on formalization in the process of construction, and did not deliberately analyze the role and position of public policy service agencies in the dissemination, as well as the users and development of fresh media construction services. Blindly emulating the success stories of new media in other fields, failing to combine the characteristics of its own research and development fields, leading to poor construction results, and no further solutions have been implemented after receiving construction results feedback, which is the current common development of the social influence construction of think tanks in China defect.

\subsection{Resource Indicator}

Number of experts reflecting the research capacity of think tanks performed excellently in the analysis results, ranking fourth in the coefficient of influence, reaching 0.029. In contrast, Number of branches or affiliates that reflect the scale of think tanks and the level of organizational framework construction, as well as Year of establishment that reflect the time and cost of the construction of think tanks, are extremely weak, with influence coefficients of -0.004 and -0.013 , which are all negative correlations.

Experts and scholars are the primary productive forces of think tanks' research capabilities and results output. The number of experts reflects the strength of human resources investment in think tanks. It is not difficult to find through the correlation matrix that the positive correlation between the number of experts and reports, the number of published books, and the number of publications all exceeded 0.6.

Number of branches or affiliates is a symbol of the level and maturity of the internal organization framework of think tanks. Studies have shown that the construction of Chinese university think tanks is far from reaching the stage of mature think tanks, indicating that the organizational structure of university think tanks is unscientific and unreasonable. Most think tanks are not conscious or have not developed to the stage of building an organizational framework. Think tanks that have been building or optimizing internal organizational frameworks have not yet achieved the effect of implementing measures. At the same time, research shows that Chinese college think tanks with a long history and long years of establishment have not shown their due advantage over new think tanks.

\section{Countermeasures and Suggestions}

\subsection{Strategic Approach Based on Research Results and Taking Advantage of Distinctive Disciplines}

Studies have shown that professional academic indicators contribute greatly to the influence of university think tanks, while professional academic indicators are measured by the output of academic results, and the correlation coefficient between the output of academic results and the number of experts is extremely high. Therefore, the author suggests that college think tanks establish a strategic policy that is oriented towards research results and gives full play to the advantages of distinctive disciplines.

The research results of think tanks in universities are the first element of the influence of think tanks, and experts and scholars are the first productive force of think tanks. Increasing the influence of think tanks depends on the arrangement of the correct strategic guidelines of think tanks with experts and scholars as the core and research results as the guidance.

Broaden the channels for the transformation of scientific research results, increase the conversion rate of research results supporting decision-making, increase the output of research results of think tanks, and promote the reform of new types of think tanks in Chinese universities. Strengthen the academic promotion mechanism, give play to the characteristics and advantages of think tanks in the professional field, cross-disciplinary integration, form a new knowledge network, lay a solid foundation for academic research, and improve the competitiveness and influence of think tanks in the professional field. Let research results go out and get publication opportunities in key journals and large conferences in the field of research, so that external experts and scholars and decision-making leaders can understand think tanks and understand the research results of think tanks.

Intensify the construction of talent teams and enhance the core competitiveness of major experts and scholars. 
Recruit experts and scholars in the field of research to cultivate internal human resource pools in think tanks. We love and cherish talents. We adopt incentive mechanisms to enhance the benefits of experts and scholars in the core position, establish an internal assessment system, and commend and motivate experts and scholars with many research results and high output quality. Carry out internal researcher training courses or lectures to share the research experience of outstanding researchers.

Talents create research results, research results inversely motivate talents, the two promote each other, build a sound talent introduction and training mechanism, expand research output channels, establish an internal incentive assessment system, and fundamentally improve the new think tanks of Chinese universities Influence.

\subsection{Adopt Flat Modern Management and Innovate Internal Governance Structure}

The research shows that the number of think tank branches or directly-affiliated institutions does not contribute strongly to the influence of university think tanks, which indicates that university think tanks lack a scientific and reasonable organizational framework and a clear governance structure. The author suggests that college think tanks adopt flat modern management and innovate internal governance structures.

Establish a modern organizational management framework, use flat-level divisions, build a matching structure of personnel and posts, and make professionals and departments at all levels full-time. Most domestic first-class universities think tanks have councils, and the leadership of the council holds the highest authority of think tanks. The leadership of the council is mostly held concurrently by the president of a university or other leaders, responsible for the formulation of major development strategies for think tanks, and controlling the research style and direction of think tanks. On the one hand, the council holds positions in schools, society, and the government at the same time. It has strong social resources and a comprehensive social network, which is conducive to establishing a channel for the transformation of think tank research results from "school" to "political". Most of the members are experts in the field of research. They have a right to speak on the research results of think tanks, which can effectively improve the credibility and influence of think tanks. This approach is scientific and effective, and it reasonably uses the internal resources of the think tank and external social relations, which is worth emulating by other think tanks.

In addition, the use of flat modern management can reduce unnecessary management levels and improve think tank operation and management efficiency. Reduce the middle leadership level of the think tank, fit the two-level management, and establish a "management" plus "operation" operating mode, so that the board of directors and other leadership can be mapped to a larger area of lower levels. By constructing a scientific and reasonable organizational framework and innovating the internal think tank structure, the influence of new think tanks in Chinese universities will be enhanced.

\subsection{Increase the Weight of Social Network Influence in the Evaluation System and Attach Importance to the Construction of New Media}

Research shows that social influence indicators have a great contribution to the influence of university think tanks and think tanks, and some authoritative evaluation systems do not give a high value to this indicator in the evaluation system, and only appear as secondary indicators or tertiary indicators. Therefore, the author suggests that university think tanks and think tank evaluation agencies should increase the weight of social network influence in the evaluation system and attach importance to the construction of new media.

Attach importance to traditional media, look at new media dialectically, explore ways to build new media, and improve the social influence of new types of think tanks in Chinese universities. The importance of traditional media to non-profit public policy research institutions is still undiminished. The audiences of traditional media such as newspapers and periodicals are more mainstream. Exposure or reference research by newspapers and periodicals has made it easier for institutions and research results to pay attention to or even recognize decision-making leadership. One of the most important channels to enhance the influence of university think tanks.

On the other hand, university think tanks need to be more cautious and pragmatic about the construction of new media. Do not follow the success stories of new media in other fields. Study and analyze the characteristics of new media construction in think tanks. For the official WeChat public account of university think tanks, institutions need to be down-to-earth to promote the quality of articles, promote the organization's excellent culture, disseminate high-quality research results, increase publicity efforts of public accounts, tap external incremental users, eliminate formal construction.

It is recommended that Chinese universities think tanks build research results sharing and promotion platforms, combined with mobile internet, to allow users to see high-quality think tank research results, to achieve the effect of sharing knowledge and creating a good think tank brand. At the same time, it researched audience users, 
combined with user needs, and provided online and offline services such as strategic consulting and mobile knowledge management to enhance user stickiness, find new user growth points, build new social networks, and innovate ways to build a new think tank for social influence in Chinese universities.

\subsection{Build a Management Information System that Meets the Needs of University Think Tanks, and Pay Attention to Resource Accumulation}

An institution with a long history should continue to accumulate resources, inherit culture, learn from experience, and develop over time. At present, the think tanks of Chinese universities do not realize the importance of this, and many outstanding think tanks have not developed and become outstanding because of their long history.

For established think tanks with a long and long history, it is recommended that think tanks establish a file management system or create an independent management information system to maximize the protection of valuable resources such as the research process, research results, personnel data, social resources, and personnel over time. Objective factors such as mobility are missing. Let the new staff be informed in their work, have experience to learn, and have a good organizational culture to pass on. In addition, for an organization with high mobility of personnel, good file management and information management can reduce the loss of talent flow. For think tanks, research results and social resources are the first element and transformation channel to achieve impact. Informatization management of the two resources is a necessary condition for becoming a first-class think tank, and it is the key to let the organization continue to develop and progress over time and enhance its influence.

For a new think tank with a short life span, give play to the young and dynamic characteristics of the organization, flexibly build an organizational framework, enjoy the policy dividends of the times, learn from the experience of established think tanks, and complete the comprehensive construction of think tanks faster and more efficiently To increase the influence of think tanks. Compared with the old think tanks, the new think tanks have good policy development conditions. Without the rigid institutional framework of the old think tanks, they can operate flexibly and efficiently through modern management methods. In addition, in the era of mobile internet, it is easier for new think tanks to innovate the path of influence building, try more experimental measures, and explore a new path for the influence construction of think tanks in Chinese universities.

\section{Summary and Outlook}

\subsection{Summary}

The full text aims to explore what are the main factors that have a key impact on the think tank's influence and to what extent. This article considers all factors that have influence on think tanks as observable specific factors, finds indicators through theoretical research, selects indicators through data research, defines indicators by constructing models, and links indicators to influence. The research uses factor analysis method, multiple regression method, normal upper percentile method and other research methods to conduct empirical research on the model. SPSS, data crawler and CTTI database are used as research tools. Through the empirical research, the influence coefficient of each index on the influence value is obtained as the empirical result of this research. The empirical results are analyzed, and the analysis is carried out from three perspectives: qualitative, quantitative, and comparative. The intention is to discover where the empirical results of the indicators come from and whether they are scientific and reasonable. Based on the research and analysis of empirical results, suggestions and suggestions are made on the construction and development of China's college think tanks and ways to enhance their influence.

From the research direction, this research is different from other think tanks in the selection direction. It advocates the combination of qualitative and quantitative, makes full use of open access resources, and starts from the results of think tank influence ranking to analyze the influence of think tank behavior on influence. The intrinsic link between relevance and behavior. Different from the construction of think tank's influence evaluation system, it requires more subjective judgments. This study advocates the use of objective facts, based on data generated by observable behaviors, focuses on quantitative research, and absorbs the opinions of domestic and foreign experts and scholars Doing qualitative research.

\subsection{Deficiencies and Outlook}

In the process of this research, there may be problems of insufficient data acquisition or mature research. The author here puts forward several points and prospects, which need to be further improved in subsequent studies.

In this study, the CTTI think tank index was used in the data acquisition. CTTI, as the only database that can solve the quantitative needs of this study, has its limitations and immatureness. CTTI is a data acquisition method in which applicants fill in information fields and review. Only think tanks filled out by applicants can query the data. Although it has covered most important think tanks, it cannot cover all domestic think tanks under construction. In addition, the applicants will inevitably make mistakes when filling in the information in the think tank, and it is 
difficult for the CTTI to achieve a $100 \%$ correction rate during the review process. As the CTTI construction becomes more complete, I believe this problem can be effectively solved.

This study used the normal upper percentile method to quantify the impact. Due to the small number of studies using quantitative ranking, it remains to be explored whether this method is the best solution. Although quantitative research is more difficult, it has important practical significance. I also hope to see more quantitative research in various fields in the future.

In the selection of indicators, due to the feasibility of data acquisition and the limited social resources of students, this study cannot cover all valid indicators, such as think tank funds and other important indicators. It is hoped that in future research, it will be improved through other channels and more diversified methods and ideas.

\section{References}

Ahmad M. (2008). US Think Tanks and the Politics of Expertise: Role, Value and Impact. Political Quarterly. https://doi.org/10.1111/j.1467-923X.2008.00964.X

Liang X. (2018). Analysis of Library Think Tank Functio. China Think Tank Newspapers.

Liang Y. (2019). 2018 CTTI College Think Tank and" Top 100 College Think Tank "report. Guangming Daily.

Mcdonald L. (2014). Think Tanks and the Media How the Conservative Movement Gained Entry Into the Education Policy Arena. Educational Policy. https://doi.org/10.1177/0895904813492372

Mcnutt K, Marchildon G. (2009). Think Tanks and the Web: Measuring Visibility and Influence. Canadian Public Policy. https://doi.org/10.3138/cpp.35.2.219

Paun, Akash. (2014). How Research can Influence Government: Some Thoughts from Thinktankland - A Response to Matthew Wood, Politics. https://doi.org/10.1111/1467-9256.12059

Qiu Junping \& Zu Wenling. (2018). Evaluation and Analysis of Chinese University Think Tank Network Impact Based on Group Analysis Hierarchy Proces. Modern Information.

Segal H, Abelson D E. (2004). Do Think Tanks Matter?: Assessing the Impact of Public Policy Institutes. Canadian Public Policy. https://www.jstor.org/stable/3552584? origin=crossref https://doi.org/10.2307/3552584

Shoup L H. (2015). Wall Street's Think Tank: The Council on Foreign Relations and the Empire of Neoliberal Geopolitics, 1976-2014. NYU Press.

Wang, J. (2006). Managing national reputation and international relations in the global era: Public diplomacy revisited. Public relations review, 32(2), 91-96.

Xu Ming. (2012). Research on the application of normal distribution to score ranking and adjustment. East China Normal University.

\section{Copyrights}

Copyright for this article is retained by the author(s), with first publication rights granted to the journal.

This is an open-access article distributed under the terms and conditions of the Creative Commons Attribution license (http://creativecommons.org/licenses/by/3.0/). 